\title{
The role of inhaled and/or nasal corticosteroids on the bronchodilator response
}

Ju Kyung Lee, M.D., Dong In Suh, M.D., and Young Yull Koh, M.D.

Department of Pediatrics, Seoul National University College of Medicine, Seoul, Korea

Received: 13 August 2010, Reviced: 17 September 2010 Accepted: 16 October 2010

Corresponding author: Young Yull Koh, M.D.

Department of Pediatrics, Seoul National University Hospital, 28 Yongon-Dong, Chongno-gu, Seoul 110-744, Korea

Tel: +82.2-2072-3631, Fax: +82.2-747-5130

E-mail: kohyy@plaza.snu.ac.kr

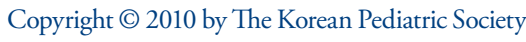

Purpose: To compare the profiles of the bronchodilator response (BDR) among children with asthma and/or allergic rhinitis (AR) and to determine whether BDR in these children is reduced by treatment with inhaled and/or nasal corticosteroid.

Methods: Sixty-eight children with asthma (mean age, 10.9 years), 45 children with comorbid asthma and AR (mean age, 10.5 years), and 44 children with AR alone (mean age, 10.2 years) were investigated. After a 2-week baseline period, all children were treated with inhaled fluticasone propionate (either 100 or $250 \mu$ g b.i.d., tailored to asthma severity) or nasal fluticasone propionate (one spray b.i.d. in each nostril) or both, according to the condition. Before and 2 weeks after starting treatment, all children were evaluated with spirometry and bronchodilator testing. BDR was calculated as a percent change from the forced expiratory volume in 1 second $\left(\mathrm{FEV}_{1}\right)$ at baseline.

Results: The mean BDR was 10.3\% [95\% confidence interval (Cl) 8.3$12.4 \%$ ] in children with asthma, 9.0\% $(95 \% \mathrm{Cl} 7.3-10.9 \%)$ in subjects with asthma and $\mathrm{AR}$, and $5.0 \%(95 \% \mathrm{Cl} 4.1-5.9 \%)$ in children with $\mathrm{AR}$ alone $(P<0.001)$. After treatment, the mean BDR was reduced to $5.2 \%$ $(95 \% \mathrm{Cl} 4.2-6.3 \%)(P<0.001)$ in children with asthma and to $4.5 \%(95 \%$ $\mathrm{Cl} 3.5-5.5 \%)(P<0.001)$ in children with asthma and AR. However, children with rhinitis showed no significant change in BDR after treatment, with the mean value being $4.7 \%(95 \% \mathrm{Cl} 3.7-5.8 \%)(P=0.597)$. Conclusion: The findings of this study imply that an elevated BDR in children with AR cannot be attributed to nasal inflammation alone and highlights the close relationship between the upper and lower airways.

Key words: Bronchodilator response, Nasal corticosteroids, Inhaled corticosteroids, Asthma, Allergic rhinitis

This is an open-access article distributed under the terms of the Creative Commons Attribution Non-Commercial License (http://creativecommons.org/licenses/by $\mathrm{nc} / 3.0 /$ ) which permits unrestricted non-commercial use, distribution, and reproduction in any medium, provided the original work is properly cited.

\section{Introduction}

There is a close relationship between asthma and allergic rhinitis $(\mathrm{AR})^{1-3)}$. Epidemiologically, asthma and AR frequently coexist ${ }^{2}$
${ }^{4)}$. Pathophysiologically, they both show eosinophilic airway inflammation ${ }^{2,5)}$. Clinically, their treatment options are similar ${ }^{6}$. In co-morbid patients, effective treatment of AR also improves asthma symptoms $s^{6,7)}$. 
The Bronchodilator response (BDR) is usually characterized by an increase in forced expiratory volumes after inhalation of a bronchodilator. It is well known that airway hyperresponsiveness to nonspecific broncho-constrictors and a substantial BDR are important characteristics of asthma ${ }^{8}$. The Assessment of the BDR in patients with asthma is widely used in clinical practice. Generally, the $\mathrm{BDR}$ is elevated in asthmatic patients ${ }^{9-12}$. In patients with AR, BDR is not used as a routine test. However, recent studies reported elevated BDR in some AR patients who had neither a history nor clinical symptoms of asthma ${ }^{13,14)}$.

In asthma, controller medication reduces airway inflammation, relieves symptoms and improves lung function ${ }^{15)}$. Regular inhalation of corticosteroids are reported to reduce BDR in asthmatic patients ${ }^{16,}$ ${ }^{17)}$. In patients with $\mathrm{AR}$, intranasal corticosteroids are recommended as a first-line therapy to reduce upper airway inflammation and to relieve rhinitic symptoms, especially nasal congestion ${ }^{18)}$. However, little is known about the changes in the BDR in patients with AR after regular administration of intranasal corticosteroids.

This study was conducted to compare BDR in children with asthma and/or AR and to investigate the effect of inhaled and nasal corticosteroids on the BDR in these patients.

\section{Materials and methods}

\section{Sulbjects}

One hundred and fifty-seven children with asthma and/or AR (mean age, 10.6 years) were enrolled in this study during the period between June 2005 and January 2010. All subjects attended the allergy clinic at Seoul National University Children's Hospital. Asthma was diagnosed by a physician with the history of recurrent episodic symptoms (cough, wheezing and dyspnea) and symptomfree intervals. All asthmatic children had airway hyperresponsiveness defined by as a provocative concentration of methacholine causing a $20 \%$ fall in forced expiratory volume in 1 second $\left(\mathrm{FEV}_{1}\right)\left(\mathrm{PC}_{20}\right)$ of $<16 \mathrm{mg} / \mathrm{mL}$. They had mild to moderate asthma and needed intermittent use of $\beta_{2}$-agonists with or without continuous use of lowdose inhaled corticosteroids to control their asthma symptoms. AR was diagnosed with the patient's history, rhinologic examination, and skin-prick test. Children with AR had recurrent symptoms of sneezing, rhinorrhea, and nasal stuffiness or itching during the preceding year. In rhinitic children, pallor or swelling of the nasal mucosa and turbinates was a frequent finding. They needed intermittent use of oral anti-histamines with or without continuous use of nasal corticosteroids to control their rhinitic symptoms. All children with AR regardless of co-morbid asthma were positive for skin-prick test. Clinical examination and chest radiograph were performed to exclude other causes of wheeze or clinically significant medical disorders apart from asthma or AR.

Parents and children provided written informed consent for their participating in the study. The Institutional Review Board of our hospital approved the study protocol.

\section{Study Design}

Subjects were divided into three groups according to their diagnosis : children with asthma, with co-morbid asthma and AR, and with AR. All subjects had a 2-week baseline period, followed by a treatment period. During the baseline period, all asthmatic children were asked to discontinue their controller medication, if used, and to use $\beta_{2}$-agonists on demand. In the baseline period, all rhinitic children were asked to discontinue oral anti-histamines and nasal corticosteroids. In the treatment period, children with asthma were asked to receive inhaled corticosteroids, children with AR to receive nasal corticosteroids, and children with co-morbid asthma and AR to receive both inhaled and nasal corticosteroids. All asthmatic children regardless of co-morbid AR used inhaled fluticasone propionate (FP) (Seretide Diskus ${ }^{\mathrm{TM}}$, GlaxoSmithKline, Middlesex, UK) twice a day. The dose of inhaled FP was tailored to asthma severity, either 100 or $250 \mu \mathrm{g}$. All children with AR used nasal FP (Flixonase ${ }^{\mathrm{TM}}$, GlaxoSmithKline, Middlesex, UK) twice a day with one spray in each nostril.

All children had undergone spirometry with the bronchodilator test at the end of the 2-week baseline period. Two weeks after starting treatment, they had undergone additional spirometry with bronchodilator test.

\section{Skin prick test}

The skin prick test was performed for the assessment of atopy. Thirteen common aeroallergens including house dust mites (Dermatophagoides pteronyssinus, Dermatophagoides farinae), animal danders (cat epithelia, dog epithelia), pollens (mugwort, ryegrass, ragweed, hazel, alder, oak), molds (Aspergillus fumigatus, Alternaria alternata), and cockroach (Blatella germanica) were used for the evaluation.

Histamine and isotonic saline were used as positive and negative controls. A mean wheal diameter of $3 \mathrm{~mm}$ or larger, in the absence of any reaction to saline solution, was considered a positive reaction. Atopy was defined as the presence of at least one positive reaction to a battery of 13 common airborne allergens.

\section{Bronchodilator test}

Forced expiratory volume in one second $\left(\mathrm{FEV}_{1}\right)$ and forced vital capacity (FVC) were measured using a computerized spirometer 
(Microspiro-HI 298, Chest, Tokyo, Japan) in accordance with the recommendations of the American Thoracic Society ${ }^{19)}$. The $\mathrm{BDR}$ is based on spirometric measurements before and after the administration of $200 \mu \mathrm{g}$ of salbutamol. Fifteen minutes after salbutamol inhalation, triplicate spirometry measurements were taken and the highest of the three $\mathrm{FEV}_{1}$ values was recorded. BDR was calculated as [(postbronchodilator $\mathrm{FEV}_{1}$-prebronchodilator $\mathrm{FEV}_{1}$ )/prebronchodilator $\left.\mathrm{FEV}_{1}\right] \times 100$. Inhaled $\mathrm{FP}$ was withdrawn at least 24 hours before spirometry and bronchodilator test. When salbutamol was used as a rescue medicine, bronchodilator test was postponed until at least 6 hours after the last dose.

\section{Statistical analysis}

Data are presented as means $\pm S D$. FEV ${ }_{1}$ and $F V C$ values are expressed as percentages of predicted values. The changes in BDR and $\mathrm{FEV}_{1}$ of each group were assessed with a two-tailed Student's paired $t$-test. To compare the degree of reduction in BDR between children with asthma and those with co-morbid asthma and AR, we used a two-tailed Student's independent $t$-test. Spirometry measurements and the BDR of the three groups were compared by one-way ANOVA using Scheffe's post hoc analysis. All P values less than 0.05 were considered statistically significant. All analyses were performed using statistical software SPSS version 12.0 (SPSS Inc., Chicago, IL, USA).

\section{Results}

The subjects' descriptive characteristics are shown in Table 1. There were no statistically significant differences in height and age between the three groups.

Spirometric measurements and BDR in the baseline period are summarized in Table 2. In prebronchodilator $\mathrm{FEV}_{1}$ and BDR, there were no statistically significant differences between children with asthma and those with co-morbid asthma and AR. Asthmatic children regardless of co-morbid AR showed a lower prebronchodilator $\mathrm{FEV}_{1}(P=0.004)$ and a higher $\mathrm{BDR}(P<0.001)$ than children with AR. Two weeks after starting treatment,

Table 1. Demographic Characteristics of the Evaluated Patients $(\mathrm{N}=157)$

\begin{tabular}{lccc}
\hline & Asthma & Co-morbid asthma and AR & AR \\
\hline Population (n) & 68 & 45 & 44 \\
Sex (M/F) & $43 / 25$ & $39 / 6$ & $30 / 14$ \\
Age (years) & $10.9 \pm 3.1$ & $10.4 \pm 2.1$ & $10.2 \pm 2.6$ \\
Height (cm) & $147.2 \pm 14.6$ & $144.3 \pm 14.1$ & $140.9 \pm 15.2$ \\
Atopy, $n(\%)$ & $54(79.4 \%)$ & $45(100 \%)$ & $44(100 \%)$ \\
\hline
\end{tabular}

${ }^{*}$ Mean \pm SD

Abbreviation : AR, allergic rhinitis there were improvements in both prebronchodilator $\mathrm{FEV}_{1}$ and postbronchodilator $\mathrm{FEV}_{1}$ in children with asthma regardless of co-morbid AR (Fig. 1). In children with asthma, after inhalation of FP, prebronchodilator $\mathrm{FEV}_{1}$ increased from $87.8 \pm 13.8 \%$ to 94.7 $\pm 12.1 \%(P<0.001)$, and postbronchodilator $\mathrm{FEV}_{1}$ also increased from $96.3 \pm 12.8 \%$ to $99.6 \pm 12.2 \%(P<0.001)$ in children with asthma. The BDR decreased from $10.4 \pm 8.5 \%$ to $5.3 \pm 4.2 \%$ in children with asthma $(P<0.001)$. An analogous result has been observed in children with co-morbid asthma and AR. After medication with inhaled and nasal FP, both prebronchodilator $\mathrm{FEV}_{1}$ and postbronchodilator $\mathrm{FEV}_{1}$ increased from $85.0 \pm 11.1 \%$ to $91.2 \pm 10.0 \%(P=0.001)$ and from $92.1 \pm 10.1 \%$ to $95.1 \pm 9.7 \%$ $(P=0.047)$, respectively. In children with co-morbid asthma and AR, the BDR decreased from $9.1 \pm 6.0 \%$ to $4.5 \pm 3.3 \%(P<0.001)$. To compare the degree of reduction in the BDR between these two groups, besides net change of $\mathrm{BDR}$, we calculated the percentage change $(\Delta \%)$ in the $\mathrm{BDR}$ with respect to values in the baseline period as following : $\triangle \% \mathrm{BDR}=[(\mathrm{BDR}$ in the treatment period$\mathrm{BDR}$ in the baseline period)/BDR in the baseline period] $\times 100$. Net change of the BDR was not significantly different between

Table 2. Spirometric Values and Bronchodilator Response at the Baseline

\begin{tabular}{lccc}
\hline & Asthma & $\begin{array}{c}\text { Co-morbid asthma } \\
\text { and AR }\end{array}$ & AR \\
\hline preBD FEV $_{1}$ (\%predicted) & $87.8 \pm 13.8$ & $85.0 \pm 11.1$ & $93.7 \pm 11.3^{*}$ \\
postBD FEV $_{1}$ (\%predicted) & $96.3 \pm 12.8$ & $92.1 \pm 10.1$ & $98.4 \pm 12.4^{*}$ \\
BDR (\%) & $10.4 \pm 8.5$ & $9.1 \pm 6.0$ & $5.0 \pm 3.0^{*}$ \\
\hline
\end{tabular}

Data are presented as means $\pm \mathrm{SD}$.

${ }^{*} P<0.05$ vs. children with asthma and with co-morbid asthma and AR. Abbreviations : AR, allergic rhinitis; preBD $\mathrm{FEV}_{1}$, prebronchodilator forced expiratory volume in one second; postBD FEV ${ }_{1}$, postbronchodilator forced expiratory volume in one second; BDR, bronchodilator response

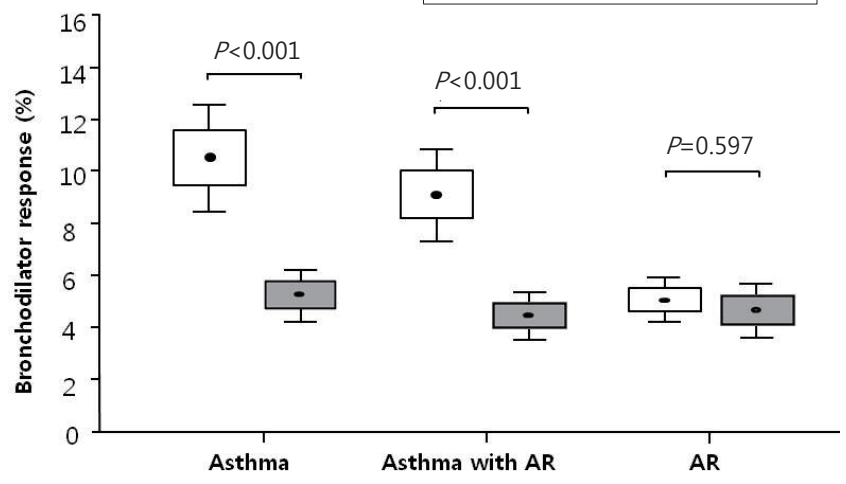

Fig. 1. BDR at baseline and after treatment with inhaled and/or nasal FP. BDR was reduced after treatment in children with asthma, irrespective of whether or not they had comorbid AR. There was no significant change in the BDR of children with AR alone. Abbreviations : BDR, bronchodilator response; FP, fluticasone propionate; AR, allergic rhinitis. 


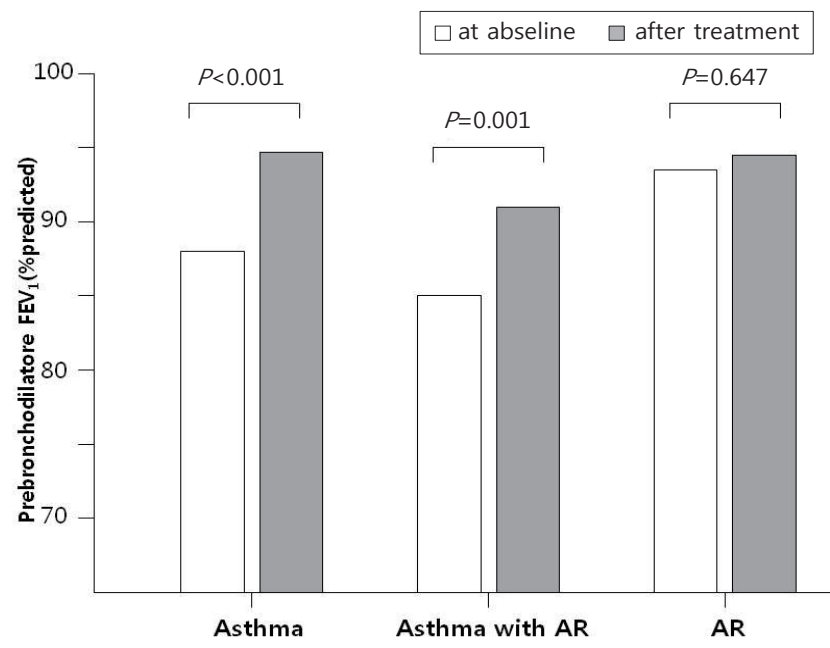

Fig. 2. Prebronchodilator $F E V_{1}$ at baseline and after treatment with inhaled and/or nasal FP. Prebronchodilator FEV $_{1}$ increased after treatment in children with asthma, irrespective of whether or not they had comorbid AR. There was no significant change in the prebronchodilator $\mathrm{FEV}_{1}$ of children with $\mathrm{AR}$ alone. Abbreviations : $\mathrm{FEV}_{1}$, forced expiratory volume in one second; FP, fluticasone propionate; AR, allergic rhinitis.

these two groups $(P=0.733)$ and $\triangle \% \mathrm{BDR}$ showed no significant difference, either $(P=0.714)$.

In children with $\mathrm{AR}$, prebronchodilator $\mathrm{FEV}_{1}$ was $93.7 \pm 11.3 \%$ and postbronchodilator $\mathrm{FEV}_{1}$ was $98.4 \pm 12.4 \%$ before treatment. Two weeks after starting treatment, their prebronchodilator $\mathrm{FEV}_{1}$ was $94.3 \pm 13.7 \%$ and postbronchodilator $\mathrm{FEV}_{1}$ was $98.8 \% \pm 14.5 \%$. However, there was no meaningful change in prebronchodilator $\mathrm{FEV}_{1}(P=0.647)$ nor in postbronchodilator $\mathrm{FEV}_{1}(P=0.797)$ after medication with nasal FP. In these children, the BDR decreased from $5.0 \pm 3.0 \%$ to $4.7 \pm 3.3 \%$ after treatment, but the change was not statistically significant $(P=0.597)$ (Fig. 2). In this study, 5 children with AR alone showed obvious BDR (of $\geq 9 \%$ ).

\section{Discussion}

We found that BDR were reduced after regular controller medication with FP in asthmatic patients regardless of combined AR. However, there were no significant changes in the BDR after regular application of nasal FP in the children with AR alone.

In this study, asthmatic children without AR had a mean BDR of $10.4 \pm 8.5 \%$, and asthmatic children with AR showed a mean BDR of $9.1 \pm 5.9 \%$ at baseline. The BDR was elevated in both groups of children compared with our previous data ( $\mathrm{n}=59$; age, $10.3 \pm 2.6$ years; BDR, $3.3 \pm 2.2 \%)(P<0.001$, one-way ANOVA). These findings correspond well with previous studies which reported elevated BDR in asthmatics ${ }^{9-12)}$. We found no significant difference in the BDR between asthmatics and the co-morbid subjects. To the best of our knowledge, however, there has been no other published data that has compared the BDR between these two groups. Previously, a few reports showed that there are no significant differences in prebronchodilator $\mathrm{FEV}_{1}$ or postbronchodilator $\mathrm{FEV}_{1}$ between asthmatic patients with and without co-morbid $\mathrm{AR}^{20,21)}$. These reports may be partially in accordance with our finding. In adults, an increase in $\mathrm{FEV}_{1}$ of at least $12 \%$ from the baseline value or an absolute change of $200 \mathrm{~mL}$ is defined as a meaningful response $^{22}$. Previous reports have suggested that BDR over 9\% would best distinguish children with asthma from those without asthma ${ }^{10,23)}$. In this study, 33 (47\%) of the 68 asthmatics and 18 (40\%) of the 45 asthmatics with AR showed a BDR of $\geq 9 \%$.

In this study, the rhinitics had a mean BDR of $5.0 \pm 3.0 \%$ at baseline. Although 5 (11\%) of the 44 rhinitics showed a BDR of $\geq 9 \%$, the rhinitics as a group showed a higher BDR value than healthy population of 59 children in our previous study ${ }^{14}$. Our finding is in good agreement with previous report of Capasso et al. ${ }^{24)}$, who showed a higher BDR in rhinitics than in normal control. However, they reported that more than $20 \%$ of rhinitics showed obvious $\mathrm{BDR}$, which was a higher percentage in comparison with this study. Several factors such as the duration of AR, basal FEV level and specific sensitization ${ }^{13)}$ should be considered to explain the discrepancy between the study and ours. Another explanation would be different dose of inhaled salbutamol in the bronchodilator testing. Previous study showed greater bronchodilator responses to inhalation of increasing doses of salbutamol ${ }^{25)}$.

An elevated BDR in children with AR may reflect co-existing bronchial inflammation ${ }^{1-3)}$. BDR is known to show a good correlation with biologic markers of lower airway inflammation ${ }^{26}$, ${ }^{27)}$. In this study, rhinitics showed a markedly lower BDR than asthmatics or asthmatics with AR. This also may be explained by the degree of lower airway inflammation in each condition. Previous studies which compared the degree of bronchial eosinophilic inflammation between rhinitic patients and asthmatic patients reported a higher percentages of eosinophils and a higher levels of ECP in induced sputum from asthmatic patients than rhinitic patients ${ }^{5,28)}$.

Regardless of co-morbid AR, our children with asthma showed a reduction in the BDR after regular use of FP. There were improvement in both prebronchodilator $\mathrm{FEV}_{1}$ and postbronchodilator $\mathrm{FEV}_{1}$ after regular treatment with FP. However, prebronchodilator $\mathrm{FEV}_{1}$ improved to a greater extent than postbronchodilator $\mathrm{FEV}_{1}$, causing of the reduction in BDR. Earlier reports showed reduction in the BDR with improvement of prebronchodilator $\mathrm{FEV}_{1}$ after treatment with inhaled $\mathrm{FP}^{16,17)}$. The improvement in $\mathrm{FEV}_{1}$ would be associated with increased airway 
caliber which was caused by anti-inflammatory effects of inhaled corticosteroids ${ }^{16,17,29,30)}$. A reduction of inflammatory cells and a decrease in release of cytokines and mediators would reduce airway wall thickness ,airway secretions and muscle tones, ${ }^{15,30)}$.

Nasal inflammation can influence the lower airway ${ }^{2,3)}$. Many reports provide evidences to support that intranasal corticosteroids improve asthma symptoms and bronchial hyperresponsiveness in asthmatic patients with $\mathrm{AR}^{31-33)}$. However, in this study, adding intranasal FP to inhaled FP would seem to bring no additional effect on the BDR. Although children with co-morbid asthma and AR used both nasal and inhaled FP, but they showed similar degree of reduction in the BDR compared to those with asthma alone. Analogous results were found in previous studies ${ }^{34,35)}$. There were no steroid sparing effect of intranasal corticosteroids when added to inhaled corticosteroids in the patients with both asthma and $\mathrm{AR}^{35}$. Although combined treatment induced reduction of systemic eosinophilic inflammation in the study, there was no additional effect on improvement in methacholine $\mathrm{PC}_{20}$.

In this study, it was an interesting finding that children with AR showed no definite changes in the BDR after regular treatment with nasal FP. A few studies have evaluated the effect of treatment with nasal corticosteroids on the biologic markers of lower airway inflammation. Sandrini et al. ${ }^{36)}$ have reported that no statistically significant effect of nasal corticosteroids on exhaled nitric oxide (ENO) in AR patients without asthma, while nasal corticosteroid meaningfully reduced ENO in the patients with co-morbid asthma and AR. Other study has reported that nasal corticosteroids improve the impaired $\mathrm{FEF}_{25-75}$ values in patients with $\mathrm{AR}^{37}$. These discrepancies would be from that these two parameters reflect different aspects of the lower airway dysfunction. $\mathrm{FEF}_{25}$ 75 is considered as a marker of small airway obstruction, which may be a sensitive indicator of early bronchial impairment in $\mathrm{AR}^{37,38)}$. Meanwhile, the BDR is known to reflect inflammations in the large airways ${ }^{39}$. It may also be possible speculation that pretreatment BDR in AR group were not great enough to show definite changes after treatment. In this study, we could not find any significant change in $\mathrm{BDR}$ after treatment even in the subgroup of rhinitic children with BDR of $\geq 9 \%$ ( $\mathrm{n}=5, P=0.094$, MannWhitney test). In addition, they showed no significant difference in prebronchodilator $\mathrm{FEV}_{1}$ at baseline period compared with other rhinitic children who did not show obvious BDR $(P=0.782$, MannWhitney test). We cannot rule out the possibility of type II error due to the small sample size. It is possible that there is some effect of nasal corticosteroids on the BDR in subgroup of rhinitic children who have a markedly elevated BDR. If it was, such effect of nasal corticosteroids on the BDR may have been demonstrable in a larger number of patients.

We evaluated the change of lung function after 2 weeks of treatment with inhaled and/or nasal FP. Previous study ${ }^{29)}$ reported that the improvement in BDR was near maximal after 2 weeks of treatment with inhaled FP. Furthermore, several studies ${ }^{35,40)}$ also demonstrated the marked improvement in nasal blockage, total nasal symptoms after 2 weeks of treatment with intranasal corticosteroids in rhinitic patients.

In conclusion, we reported an elevated BDR in children with asthma and/or AR, and a significant reduction in the BDR after treatment with inhaled corticosteroids. Children with AR also showed a higher BDR than previously reported values in normal population, but they showed no significant changes in the BDR after treatment of nasal inflammation. This implies other physiologic factors in AR patients which induce elevated BDR besides their nasal inflammation.

\section{References}

1) Corren J. Allergic rhinitis and asthma: How important is the link? J Allergy Clin Immunol 1997;99:S781-6.

2) Togias A. Rhinitis and asthma: Evidance for respiratory system integration. J Allergy Clin Immunol 2003;111:1171-83.

3) Bousquet J, Vignola AM, Demoly P. Links between rhinitis and asthma. Allergy 2003;58:691-706.

4) Blair H. Natural history of childhood asthma: 20-year follow-up. Arch Dis Child 1977;52:613-9.

5) Alvarez MJ, Olaguibel JM, Garcia BE, Rodriguez A, Tabar AI, Urobiola E. Airway inflammation in asthma and perennial allergic rhinitis. Relationship with nonspecific bronchial responsiveness and maximal airway narrowing. Allergy 2000;55:355-62.

6) Koh YY, Kim CK. The development of asthma in patients with allergic rhinitis. Curr Opin Allergy Clin Immunol 2003;3:159-64.

7) Reed CE, Marcoux JP, Welsh PW. Effects of topical treatment on asthma symptoms. J Allergy Clin Immunol 1988;81:1042-7.

8) Ulrik CS, Postma D, Backer V. Recognition of asthma in adolescents and young adults: Which objective measure is best? J Asthma 2005;42:54954.

9) Koga T, Kamimura T, Oshita Y, Narita Y, Mukaino T, Nishimura M, et al. Determinants of bronchodilator responsiveness in patients with controlled asthma. J Asthma 2006;43:71-4.

10) Dundas I, Chan EY, Bridge PD, Mckenzie SA. Diagnostic accuracy of bronchodilator responsiveness in wheezy children. Thorax 2005;60:13-6.

11) Kumar R, Wang B, Wang X, Chen C, Yang J, Fu L, et al. Bronchodilator responses in Chinese children from asthma index families and the general population. J Allergy Clin Immunol 2006;117:1257-63.

12) Tantisira KG, Fuhlbrigge AL, Tonascia J, Van Natta M, Zeiger RS, Strunk RC, et al. Bronchodilation and bronchoconstriction: Predictors of future lung function in childhood asthma. J Allergy Clin Immunol 2006;117:1264-71.

13) Ciprandi G, Cirillo I, Pistorio A, La Grutta S, Tosca M. Impact of allergic 
rhinitis on asthma: effects on bronchodilation testing. Ann Allergy Asthma Immunol 2008;101:42-6.

14) Suh DI, Lee JK, Lee JH, Koh YY. Bronchodilator response and its relationship to bronchial hyperresponsiveness in children with allergic rhinitis/asthma. Pediatr Allergy Respir Dis 2010;20:59-67.

15) Morris HG. Mechanisms of action and therapeutic role of corticosteroids in asthma. J Allergy Clin Immunol 1985;75:1-13.

16) Kerstjens HA, Brand PL, Quanjer PH, van der Bruggen-Bogaarts BA, Koëter GH, Postma DS. Variability of bronchodilator response and effects of inhaled corticosteroid treatment in obstructive airway disease. Dutch CNSLD Study Group. Thorax 1993;48:722-9.

17) Faul JL, Demers EA, Burke CM, Poulter LW. Alterations in airway inflammation and lung function during corticosteroid therapy for atopic asthma. Chest 2002;121:1414-20.

18) Mygind N, Dahl R. The rationale for use of topical corticosteroids in allergic rhinitis. Clin Exp Allergy 1996;26:2-10.

19) American Thoracic Society. Standardization of spirometry: 1994 update. Am J Respir Crit Care Med 1995;152:1107-36.

20) Ponte EV, Franco R, Nascimento HF, Souza-Machado A, Cunha S, Barreto ML, et al. Lack of control of severe asthma is associated with coexistence of moderate-to-severe rhinitis. Allergy 2008;63:564-9.

21) Jang AS, Park JS, Lee JH, Park SW, Kim DJ, Uh ST, et al. Asthmatics without rhinitis have more fixed airway obstruction than those with concurrent rhinitis. Allergy Asthma Immunol Res 2010;2:108-13.

22) American Thoracic Society. Lung function testing: selection of reference values and interpretative strategies. Am Rev Respir Dis 1991;144:1202-18.

23) Galant SP, Morphew T, Amaro S, Liao O. Value of the bronchodilator response in assessing controller naïve asthmatic children. J Pediatr 2007;151:457-62.

24) Capasso M, Varricchio A, Ciprandi G. Impact of allergic rhinitis on asthma in children: effects on bronchodilation test. Allergy 2010;65:2648.

25) Lipworth BJ, Clark RA, Dhillon DP, Brown RA, McDevitt DG. $\mathrm{B}$-adrenoreceptor response to high doses of inhaled salbutamol in patients with bronchial asthma. Br J Clin Pharmacol 1988;26:527-33.

26) Covar RA, Szefler SJ, Martin RJ, Sundstrim DA, Silkoff PE, Murphy J, et al. Relations between exhaled nitric oxide and measures of disease activity among children with mild-to-moderate asthma. J Pediatr 2003;142:46975 .

27) Colon-Semidey AJ, Marshik P, Crowley M, Katz R, Kelly HW. Correlation between reversibility of airway obstruction and exhaled nitric oxide levels in children with stable bronchial asthma. Pediatr Pulmonol

\section{0;30:385-92.}

28) Spanevello A, Migliori GB, Sharara A, Ballardini L, Bridge P, Pisati $\mathrm{P}$, et al. Induced sputum to assess airway inflammation: a study of reproducibility. Clin Exp Allergy 1997;27:1138-44.

29) Faul JL, Leonard CT, Burke CM, Tormey VJ, Poulter LW. Fluticasone propionate induced alterations to lung function and the immunopathology of asthma over time. Thorax 1998;53:753-61.

30) Szefler SJ, Martin RJ, King TS, Boushey HA, Cherniack RM, Chinchilli VM, et al. Significant variability in response to inhaled corticosteroids for persistent asthma. J Allergy Clin Immunol 2002;109:410-8.

31) Agondi RC, Machado ML, Kalil J, Giavina-Bianchi P. Intranasal corticosteroid administration reduces nonspecific bronchial hyperresponsiveness and improves asthma symptoms. J Asthma 2008;45:754-7.

32) Reed CE, Marcoux JP, Welsh PW. Effects of topical nasal treatment on asthma symptoms. J Allergy Clin Immunol 1988;81:1042-7.

33) Mygind N, Dahl R, Nielsen LP. Effect of nasal inflammation and of intranasal anti-inflammatory treatment on bronchial asthma. Respir Med 1998;92:547-9.

34) Nathan RA, Yancey SW, Waitkus-Edwards K, Prillaman BA, Stauffer JL, Philpot E, et al. Fluticasone propionate nasal spray is superior to montelukast for allergic rhinitis while neither affects overall asthma control. Chest 2005;128:1910-20.

35) Nair A, Vaidyanathan S, Clearie K, Williamson P, Meldrum K, Lipworth BJ. Steroid sparing effects of intranasal corticosteroids in asthma and allergic rhinitis. Allergy 2010;65:359-67.

36) Sandrini A, Ferreira IM, Jardim JR, Zamel N, Chapman KR. Effect of nasal triamcinolone acetonide on lower airway inflammatory markers in patients with allergic rhinitis. J Allergy Clin Immunol 2003;111:313-20.

37) Kessel A, Halloun H, Bamberger E, Kugelman A, Toubi E. Abnormal spirometry in children with persistent allergic rhinitis due to mite sensitization: The benefit of nasal corticosteroids. Pediatr Allergy Immunol 2008;19:61-6.

38) Ciprandi G, Cririllo I. The lower airway pathology of rhinitis. J Allergy Clin Immunol 2006;118:1105-9.

39) Puckett JL, Taylor RW, Leu SY, Guijon OL, Aledia AS, Galant SP, et al. An elevated bronchodilator response predicts large airway inflammation in mild asthma. Pediatr Pulmonol 2010;45:174-81.

40) Wilson AM, Orr LC, Sims EJ, Lipworth BJ. Effects of monotherapy with intra-nasal corticosteroid or combined oral histamine and leukotriene receptor antagonists in seasonal allergic rhinitis. Clin Exp Allergy 2001;31:61-8. 